\title{
Mediated Superficiality and Misogyny Through Cool on Tinder
}

Social Media + Society July-September 2019: I-11 (C) The Author(s) 2019 Article reuse guidelines: sagepub.com/journals-permissions DOI: $10.1177 / 2056305119872949$ journals.sagepub.com/home/sms (S)AGE

\author{
Jin Lee ${ }^{\mathbb{D}}$
}

\begin{abstract}
Signaled in its reputation as a "hookup app" or "sex app," the mobile dating app Tinder has been accused of having ignited "hookup culture" associated with superficiality and sexual innuendo. However, little is known about how Tinder has obtained this notoriety and what Tinder is actually responsible for. This study analyzes talks about Tinder on Reddit (/r/Tinder), as part of Tinder culture where Tinder discourse and norms are established and shared in relation to broader youth pairing culture. Through a lens of feminist media scholarship, I show that an association between Tinder and hookups is couched in a gendered code of conduct, coolness. I argue that this gendered coolness in the economy of visibility of Tinder evokes and justifies misogyny online in line with the sexism inherent to hookup culture.
\end{abstract}

\section{Keywords}

Tinder, visibility, cool, hookup, online misogyny

\begin{abstract}
Online dating, particularly Tinder, is bad for us (millennials) as a generation. I used to always criticize it for being like a Baelish whore house, ordering up another human being to your door like a pizza, but I now realize it's really much worse than that. It's actually tearing apart the fabric of gender relationships. It's far more superficial than just regular old school dating, and now we're seeing it used to reinforce stereotypes by both sexes.
\end{abstract}

—from $/ \mathrm{r} /$ Tinder

The mobile dating app Tinder has been accused of having ignited "hookup culture" almost as the "apocalypse" of modern love for its easiness and fastness in meeting people for intimacy (Sales, 2015). Launched in September 2012, the app is leading the online dating market over "traditional" online dating sites (e.g., OkCupid, Match.com) and is particularly popular among the youth: it has more than 50 million users in 196 countries, and $83 \%$ of users are between 16 and 34 years old, according to statistical data from 2015 (Iqbal, 2019). Utilizing users' location-based information, the app provides a streaming list of visual cards of other users within a particular radius. Users can narrow or broaden the pool of cards by adjusting settings about users' desired age range, gender, and search distance. Users choose potential partners by swiping cards to either the right (like) or left (dislike) side; when two users both swipe to the right, the display pans out as a match and enables direct messaging between them. Despite its reputation for being a "hookup app" or "sex app," its use is individualized, and thus likely to be varied, depending on how users engage with each match and develop it further. Without functions of sharing or group chatting, each match remains privately between the two parties of the match.

Echoed in the quotation above, the perception of Tinder as a hookup app arouses concerns about superficiality and violence intrinsic to online intimacy and hookup culture. The online shopping-like experiences on dating apps, like Tinder and Grindr, contribute to violence by considering others as objects to consume for instant desire: people "order" people from apps, jump into sex without much intimacy established, and discard them when their business is finished (Conner, 2019; Sales, 2015; Shield, 2017). Toxic masculinity, the "constellation of socially regressive male traits that serve to foster domination, the devaluation of women, homophobia, and wanton violence," is an exemplar of such online violence (Kupers, 2005, p. 714). Feminist scholars are worried about increasing toxic masculinity on Tinder in relation to hookup culture, where women are sexualized, evaluated, and consumed by men to instantly satisfy their lust for female flesh (Hess \& Flores, 2018; L. Thompson, 2018).

While women are certainly vulnerable in hookups via Tinder as such, little is known about how Tinder has obtained

Southern Illinois University Carbondale, USA

Corresponding Author:

Jin Lee, College of Mass Communication and Media Arts, Southern Illinois University Carbondale, I 100 Lincoln Drive, Carbondale, IL 6290I, USA.

Email: shuomach@siu.edu 
this notoriety and what Tinder is actually responsible forthat is, for letting casual sex percolate in the youth culture or for helping men act as womanizers sending direct sexual innuendos to women. Without considering these issues, it is easy to blame women who experienced mistreatment on Tinder for just using the apparent hookup app entailing sexual harassment. In this essay, I examine a subreddit about Tinder, $/ \mathrm{r}$ /Tinder, and the ways that redditors talk about Tinder in relation to gender scripts about women. I ask the following questions: (1) What is the dominant reading of Tinder? (2) Based on the reading, how do people establish Tinder norms related to hookup culture? and (3) How does this affect the shaping of Tinder culture? In doing so, I show that an association between Tinder and hookups is couched in a gendered code of conduct, coolness. I argue that this gendered coolness in the economy of visibility of Tinder evokes and justifies misogyny online in line with the sexism inherent to hookup culture.

\section{Tinder, Cool, and Economy of Visibility}

To begin, I review several concepts that inform this study, including the psychological self, the economy of visibility, and coolness in youth pairing culture. Tinder and $/ \mathrm{r} /$ Tinder are situated at the intersection of gender, heterosexual intimacy, and visual culture. This contributes to my analysis of $/ \mathrm{r} /$ Tinder as part of the contemporary youth culture of intimacy facilitated by media like Tinder. The technological settings of Tinder distinguish it from other traditional online dating sites. Unlike those sites accompanying questionnaires about one's information (e.g., demographics, hobbies) at the initial stage of signing up for the services, Tinder emphasizes the visualization of users based on their pictures that are uploaded to Tinder accounts or linked to other visual-centered platforms (i.e., Facebook, Instagram). Such image-centeredness accords with Tinder's gamified design based on a card game. The adaptation of a card game, such as streaming visual cards of users and swiping cards, transforms and presents intimacy within contexts of game playing, which leads users to derive fun from playing with the app (see Deterding, Dixon, Khaled, \& Nacke, 2011). This playful sense is maximized at the moment of matching as a new screenshot pops up with a joyous ringtone and notifies users to send a message. For the playful sense, however, users must continue to play the Tinder card game-swiping cards continuously based on instant judgments of visual cards rather than devoting efforts to "one" match. By explicitly asking if users would like to "keep swiping" after a match, the app's gamified design allows users not to interrupt their game flow for fun.

Unlike Tinder, traditional online dating sites have aligned with psy-discourses by emphasizing "the psychologization of self" (Illouz, 2007). This "new way of imagining the self vis-à-vis one's past in the language of psychology" became the common way of seeing in modern society (Illouz, 2007, p. 7). In this vein, modern intimacy has served as a site where a person can discover one's essence that is stable and unique enough to define "who I am" and distinguish the self from others by interrogating one's psyche and reformulating relationships (Barker, Gill, \& Harvey, 2018; Illouz, 2007). Intimate relationships came to be understood as two persons engaging with each one's psychological self - the ontological entity formed with core psychological properties (Barker et al., 2018; Illouz, 2007).

Illouz (2007) argues that traditional online dating services have materialized a way of building intimacy through the finding of the psychological self. She continues, "the self is constructed by breaking it down into discrete categories of tastes, opinion, personality, and temperament" based on provided answers to questionnaires that are required at the signup stage (p. 78). Therefore, building a relationship via online dating becomes a matter of finding a profile whose psychological entity is performed and thus reified in the same or similar category of one's own psychological self (Illouz, 2007).

The gamified and visual-centered settings of Tinder, however, provide little room for establishing users' psychological entities. A 500 word-limit description of oneself for a "user bio" is insufficient to show a person's complicated psyche. Furthermore, Tinder users are more likely to instantly make partner choices based on visual cards, not looking at bios, for the Tinder game flow (Duguay, 2017; Peterson, 2014a). Instead, due to its strict visual-centered design, ways to grasp other users are limited to collecting pieces of visual cues on cards and interpreting them based on racial/gender/class stereotypes, and submitting them to the imagination of a subject as an entity of visibility (Duguay, 2017; Peterson, 2014a). According to Illouz (2007), modern dating culture has been shaped in market logics; interactions for intimacy are framed as economic transactions of value between people. While such transactions occurred through the circuit of psychological registers in traditional online dating sites (Illouz, 2007), on Tinder, it does so through the circuit of visibility because its visual centered settings hamper the imagination of a psychological entity in the way that it used to be in traditional online dating. In this manner, on Tinder, the principle of the psychological self in modern intimacy is replaced with the economy of visibility.

The economy of visibility is "the epistemology of the visual that underlies both race and gender: that process of corporeal inscription that defines each as a binary, wholly visible affair" (Wiegman, 1995, p. 8). Inferring to visible signs of a body (e.g., skin color, skull shape) as primary markers of one's status, the system genders, races, and classes the body and locates the body in different strata where a level of "making oneself visible" is differently warranted (Wiegman, 1995). For example, Black bodies were not eligible to be seen and remained invisible for their undesirability, as opposed to highly visible bodies of social normativity-representatively well-toned, young, White, female 
bodies - in daily life including media (Banet-Weiser, 2018; Wiegman, 1995).

In the contemporary mediascape, visibility is economic value itself. It is because visibility is directly concerned with revenues based on whether the visibility of each image or product has consumer appeal, outrivals the visibility of other images and products, draws more attention from audiences, and is popularly consumed (Banet-Weiser, 2018). This economic function of visibility dovetails with neoliberal doctrine presenting the social world as "made up of markets, and spaces of potential competition that need to be organized as markets, blocking other narratives from view" (Couldry, 2010, p. 7). Furthermore, given the neoliberal market principle that presumes market competition as a site of fairness, neutrality, and objectivity (Adkins \& Lury, 2011), political meanings of visibility are foreclosed by the seeming image of equality (Banet-Weiser, 2018; Gray, 2013). Visibility, in turn, becomes only a matter of economies, such as competition with others for visibility on media, economic exchange for profit and more visibilities, and presenting oneself in the best manner based on the accumulated visibilities to maximize profits (Banet-Weiser, 2018). The economy of visibility, therefore, privileges an investment in the visible self aligned with social normativity vis-à-vis race, gender, sexuality, and class (BanetWeiser, 2018; Wiegman, 1995). The system continues to operate in image-centered social media like Instagram where users are induced to brand themselves to distinguish from others by showing their repository of taste consisting of visibilities (Abidin, 2014; Banet-Weiser, 2012).

The cool girl figure is a prime example of a way of selfbranding among young women at the intersection of the economy of visibility and the gender system. Consumer culture has produced figures of socially desirable femininity, who appear to be slightly different in response to changing times and trends but fundamentally continue to serve for the gender system (Peterson, 2014b). In tandem with rebellious youth movements in the 1970s, media began to produce cool discourse, adopting Black male resistance (Pountain \& Robins, 2000). By fantasizing and selling images of sexual promiscuity and thrill-seeking implied in the stereotype of Black masculinity, consumer culture successfully met the concurrent rebellious atmosphere while preserving the old gender system (Frank, 1998; Pountain \& Robins, 2000). The cool girl figure represents the working of the gender system and the consumer society's libidinal fantasy-a girl who upholds the rebellious spirit, particularly about sexual freedom and pleasure, and possesses properties of femininity that are fantasized about by men in their heterosexual lust for female flesh (Frank, 1998; Peterson, 2014b; Pountain \& Robins, 2000). The resultant cool girl figure has been welcomed by both men and women for her featured modern spirit of freedom and independence, unlike the obsolete image of passivity and excessive femininity in "girly girls" (Peterson, 2014b; Pountain \& Robins, 2000; R. Thompson,
2019). The figure neatly fits into postfeminism - the contemporary cultural landscape where young women's sexual freedom and pleasure are celebrated, including hookup culture (R. Thompson, 2019).

Characteristics of the sexual revolution in the 1970s have percolated into hookup culture as part of youth pairing culture, as opposed to traditional courtship, including prioritized sexual freedom and pleasures, avoidance of emotional engagement, and instant consumption of intimacy (D'Emilio $\&$ Freedman, 1989). Within this context, hooking up became popular among young adults as a cultural phenomenon imbued with cool discourse. Hookup is a slippery term with no clear definition, but it indicates a variety of intimate relationships that are mainly associated with game-like playing for sexual pleasure, with some chance to develop into "romance," yet do not guarantee any commitment beyond (Bogle, 2008, p. 29). Cool discourse provides a perfect script for hookups, guiding how to engage in relationships and what to prioritize in the relationships. It asks to restrict emotionality but to seek thrills, including hedonistic sexual pleasure, which consumer culture has visually adopted in commercials to eroticize heterosexuality (Peterson, 2014b; Pountain \& Robins, 2000).

Notably, hookup culture has never been equally available for women, despite its image of freedom and rebellion against patriarchy. Studies about hookup culture criticize a sexual double standard inherent to the culture in which women's sexual agency is self-regulated by the social contempt toward sexually active women as "sluts," unlike men (Bogle, 2008; Freitas, 2013; Levy, 2010). Freitas (2013) and Levy (2010) argue that hookup culture is based on patriarchal fantasies intrinsic to pornography, in which women cannot leave the status of submissive and sexualized objects to their male counterparts. Thereby, cool discourse is valorized by a gender script and invites women to hookup culture with a slight flavor of sexual freedom, upon the premise that they follow this women's version of cool, which is encapsulated in the cool girl figure.

The cool girl embodies a mixture of masculine and feminine qualities in a "balanced" way. The balance is the most crucial attribute of the cool girl figure in that she must be heterosexually attractive, with a conventionally desirable feminine body, but she should also be "laidback" in accommodating male culture, uncritically following men's performance of masculinity (e.g., laughing at men's dirty jokes, joining hookups), and thus can reassure values of masculinity (Peterson, 2014b; R. Thompson, 2019). However, when women break the balance by stepping into male territory, they become a threat to male hegemony and are castigated (Gill \& Kanai, 2018). Interestingly, the economy of visibility instigates this gender conflict.

Misogyny breaks out online as a form of popular culture, what Banet-Weiser (2018) calls popular misogyny, where women seem to win visibility thanks to the popularization of (post)feminism, and men feel themselves to be weak and 
losing in the economy of visibility. Thus, aiming to "reset the gender balance back to its "natural' patriarchal relation," popular misogyny attacks visible women through the media (BanetWeiser, 2018, p. 156). Heterosexuality becomes the site where popular misogyny competes for visibility against women because heterosexuality has been a site of validation for both men and women by assigning gender-specific responsibilities, thus binding them together in mutually supportive roles for the social status quo (Hartmann, 1981). Banet-Weiser (2018) maintains that popular misogyny sees heterosexuality within a zero-sum game logic and attempts to retake a score through a "revaluation of values" that, in effect, devalues women (p. 156). The devaluation of women includes female objectification, slut-shaming, and the consumption of heterosexual intimacy as a means to "recover" masculinity.

Within this context, popular misogyny finds a home in hookup culture, in which women and sex are considered as objects of consumption for the pornographic fantasy (Freitas, 2013). When women do not abide by the female version of coolness in the hookup script, misogyny can break out because they disturb the "natural" gender balance. Seen from this perspective, a nexus between Tinder and hookup culture, connected through the economy of visibility, needs to be examined in relation to how users read Tinder and shape its culture by (dis)allowing and establishing norms on Tinder.

\section{Method}

As part of my ethnography on Tinder, this article covers my unobtrusive observation on /r/Tinder, a subreddit about Tinder in the online discussion forum Reddit. Rather than analyzing content posted on the page to attest its veracity by projecting into "real use," I engaged the site through an ethnographic lens that aims at a "textual construction of reality" (Atkinson, 1970/2014) regarding how each comment engages with other posts, $/ \mathrm{r} /$ Tinder, and Tinder overall. I considered Tinder as a field in the Bourdieusian sense - a "social arena within which struggles and maneuvers take place over specific resources or access to such resources" (Jenkins, 1992/2007, p. 84). From this standpoint, I regarded /r/Tinder as a kind of reflection and subfield of Tinder culture, which evolves around the connection of cultural meanings and resources regarding sexual intimacy that are scattered offline and online, rather than a fixed online space as opposed to offline (Hine, 2000). My ethnographic engagement through unobtrusive observation on $/ \mathrm{r} /$ Tinder was, therefore, to reconstruct stories about Tinder culture by observing how a common way of reading Tinder forms shared understandings and norms about Tinder and may produce collective experiences in the broader youth pairing culture.

As noted above, because of its exclusively individualized setting for communication, any collective experience or narrative about Tinder can only be imagined by users, if present at all. For this reason, user experiences related to Tinder as a hookup app need to be explored via the sharing and constructing experiences of a group of Tinder users who dwell in a place organized around Tinder. As an example of the place, / $\mathrm{r}$ /Tinder is worthy to be studied because of Reddit's social sharing function.

Reddit's karma system with an emphasis on user anonymity serves Reddit as a site of social sharing. The karma system is a basic feature that facilitates discussions on Reddit by moving up or down each post based on its accumulated karma scores submitted by readers (called redditors). The system contributes to shaping cultures of subreddits, as each post is evaluated based on cultural codes and norms that are shared within the particular subreddit community (Van der Nagel, 2013). This is bolstered by user anonymity afforded by rules of each subreddit and features like moderators and throwaway accounts. Moderators in each subreddit page monitor user behaviors and often delete or ban those who troll, reveal one's personal information, or verbally attack others, which are written on the righthand side of each subreddit page. In addition, anyone can join Reddit discussions by creating temporary "throwaway" accounts, not necessarily going through sign-up steps that often require personal information, including email addresses. This feature enables people to dissociate themselves from their Reddit identity at their convenience (De Choudhury \& De, 2014; T. O’Neill, 2018).

Reddit's discussion-based feature with promised anonymity distinguishes itself from other social media (e.g., Twitter, Facebook) as a site of social sharing, including self-disclosure, support-seeking, and counseling regarding personal issues (De Choudhury \& De, 2014; T. O’Neill, 2018). Given that Tinder experiences involve personal issues related to sexual intimacy and geolocation, the anonymous environment of $/ \mathrm{r} /$ Tinder may be appealing as a safe place to talk to others about personal topics beyond one's geolocation, compared with other media.

Created in February 2013, /r/Tinder is popular. It entered the top 200 subreddits in 2016 and has 2,178,861 readers as of May 2019 (/r/Tinder, 2019). On /r/Tinder, people post their Tinder stories or image profiles of themselves or others and open discussions related to their experiences, asking for advices or sharing their tips. With the karma system, these are automatically submitted to a vote. Although posts with the highest votes appear at the top of the front page, there are two threads always on the top of the front page, entitled "Profile Review - date of each week (e.g., February 05, 2018)" and "Story Time - date of each week" in which users can submit their post, avoiding a chance to remain unviewed but pushed to the next pages. This demonstrates the social sharing function of $/ \mathrm{r} /$ Tinder in respect to Tinder in general.

Reddit is, however, notorious as a "manosphere" imbued with misogyny and men's rights activism (Mantilla, 2015; Massanari, 2017; Milner, 2013). For this reason, my data from $/ r$ /Tinder do not show the whole picture of Tinder culture but remain as a sample that might be influenced by male-dominant discourses. Yet, it is crucial to see how biased Tinder discourse can take part in shaping the broader culture 
of Tinder regarding recent gender conflicts and (hetero)sexual intimacy online. Considering that the display of hegemonic masculinity is encouraged in hookup scenes (Currier, 2013; Freitas, 2013), it is worthy to discuss how the reading of Tinder on $/ \mathrm{r} /$ Tinder in relation to its reputation as a "hookup app" resonates in such a manosphere.

During my 3-month observation of $/ \mathrm{r} /$ Tinder from February to April, 2018, I collected 45 threads that contained an average of 52.6 comments (ranging from three to 478 comments) - 1,562 comments in total, written between February 2013 and April 2018. As part of my research project that studies non-White females' use of Tinder in the United States, I initially planned to identify discourses that non-White females interact with in relation to their racial and gender identities and the broader Tinder culture. Due to the anonymity of Reddit, however, it was difficult to identify one's gender and race and to associate those factors with Tinder culture. While race was not salient in posts, ${ }^{1}$ gender was often noted by referring to a conventional gender script. Topics about nonheterosexuality were also rarely found, presumably because of heteronormative settings of Tinder (Duguay, 2017); thus, this article is based on heterosexuality.

Focusing on gender, heterosexuality, and overall Tinder culture, I examined (1) talks that female redditors interacted with and (2) flows and patterns across threads and themes pertaining to gendered hookup culture. By doing so, I analyzed $/ \mathrm{r} /$ Tinder as a site of interactions between redditors and between individual experiences and collective stories about Tinder, manifested in the structure of each post, including posts consulting personal Tinder experiences, asking for others' advice or similar experiences for sympathy, expressing difficulties in using Tinder, and accumulating or providing Tinder norms to readers, in reference to gender norms - all of which shaped a broader image of Tinder as part of youth pairing culture. All the quotations in this article are verbatim. To protect user anonymity, I deleted the redditors' IDs, but I indicated the users' gender when I was able to identify it for the purpose of this study. To analyze /r/Tinder, first I show how redditors read Tinder. Second, I extend this to focus on how users establish Tinder norms in relation to hookup culture and the app's visual-centeredness. Finally, I examine how such norms spread a misogynistic tone inherent in skepticism toward female Tinder users.

\section{Tinder $=$ Hookup}

A lot of people, I've noticed, are now posting on their profile things like "NOT here for hookups" or "If you're looking for ass swipe left" or other dumb shit like that. Totally forgetting that Tinder is a damn sex app ... This isn't match.com or POF [PlentyOfFish] or a "Dating" site at all ladies and gentlemen ... This is Tinder, the booty call app. Get it right.

People on $/ \mathrm{r} /$ Tinder distinguished Tinder from other online dating services and offline dating, referring to fun originating in Tinder's visual-centeredness. As part of its gamified design, the visual-centeredness prioritizes playfulness and fun. Unlike traditional dating in which fun is sought around dating-leisure activities like moviegoing (Bailey, 1989; Illouz, 1997), the mobility of Tinder as a smartphone app promises the sense of fun and playfulness transcending time and place. People on $/ \mathrm{r} /$ Tinder, therefore, considered Tinder as a convenient tool for fun: "Just to talk to people when I'm bored, maybe eventually meet up with someone" (female); "I'm on Tinder more for fun than anything" (female).

Features of fun, such as temporality, lightness, and escape from seriousness and duties (Fincham, 2016), resonate in hookup culture, mainly associated with game-like playing for sexual pleasure (Bogle, 2008). People on /r/Tinder identified the highlighted fun of Tinder with such attributes of hookup culture, as opposed to courtship that requires emotional work by both parties in a relationship to develop and maintain intimacy (Illouz, 1997). From this base, the link between Tinder and hookups is made, as opposed to longterm relationships and other traditional online dating sites, taking a discursive form on /r/Tinder: "As a girl (20 F) I can definitely tell you that you can use Tinder for casually hooking up"; "I got out of a 3 year relationship and wanted to just casually hook up with guys/meet new dudes and Tinder has definitely helped me do that" (female); "I take this very casually and had a lot of fun meeting different guys, I've had way more fun dates/experiences from Tinder vs. OKC [OkCupid] or in real life." The fun of Tinder seemed appealing to those who recently ended long-term relationships because such fun is often restricted in traditional courtship for monogamous commitment (Illouz, 1997).

While the identification of Tinder and hookups was salient, redditors' real use of Tinder seemed not always to match with it. Many mentioned disconnections from the matched users, including "no response after being matched," "ghosting after exchanging a few conversations," and "no show at offline meetings." What interested me, however, was how the "fun" of Tinder was addressed regardless of the actual hooking-up activities offline.

I have more fun going out without a date, so if there is any kind of hint that he won't look like his photos or it's not going to be a fun time, I'll flake. (Female)

I would guess about half the people on there see it as a fun ego boosting game, not to actually meet up.

While fun on traditional online dating sites has manifested as a performative attribute to build the psychological self via profiles (e.g., profiles read "I am fun and funny," Illouz, 2007), fun on Tinder appears as an object to consume via its technological features related to users' visibilities. Echoing the card-game setting, fun appears as a reward granted by joining Tinder, which can be pursued at various stages of paring, from gazing visual cards to swiping, to matching, not 
necessarily meeting offline. As the app is gamified, geared toward fun from the early stage of its use in this manner, playing Tinder as a game must continue to gain more fun as reward, rather than focusing on "a date" or "an actual meetup." This is possible when a code of conduct is observed. In posts asking for or giving advice, the code of conduct was delineated regarding self-presentation, pickup lines to initiate a conversation, and ways of reacting to matches - all of which were voiced into a simple tip: "be cool."

\section{Be Cool}

Cool is mainly concerned with two aspects: restrictive emotionality and visual presentation (Pountain \& Robins, 2000). The two aspects work together in the performance of coolness; the greater the absence of emotionality in performance, the more visibly cool the presentation (Stearns, 1994). Tinder's image-focused features with relatively insufficient room for building the psychological self via profiles help set cool as Tinder's code of conduct.

As an attitudinal norm, cool was addressed on /r/Tinder as nonchalance in absentia of emotional and affective pulls to matched partners. On Tinder, as opposed to traditional courtship, casualness should be constantly conveyed through conversations:

It's fine for guys to insinuate hanging out earlier like on something like, "oh cool, we should hang out sometime," or "let me know next time you're in the area," but not really make concrete plans until we talk more. (Female)

Say "I am looking for fun, casual time with women, and if we hit it off, great. You?" Geez gotta do everything for you.

I mostly get "Hey," "You are cute" or "I like your hair" as a first message. For me, this is ok and does not sound desperate at all in my ear. (Male)

The accounts above advised against getting too intimate with or too serious or committed to matches. Any hint of serious interest in matched partners, including expectations to further matches into concrete forms of offline dating with "concrete plans," may sound "desperate." Although a match is a result of mutual interest in each other, the interest should be kept private to let the match flow, just as players never show all their cards on the table to win at card games.

Based on the "Tinder = hookup" logic, some redditors considered Tinder matches impervious to norms of traditional courtship, and they even showed their belittling attitudes toward courtship as "uncool" or "drama": "I wouldn't go with babe or sweetheart. That shit turns me off at least, that's like boyfriend shit. No one is on Tinder for boyfriend shit" (female). This redditor shared her communicative practices on Tinder as if advice for others not to use certain types of language like "babe" and "sweetheart" that are associated with courtship. By doing so, she shunned the potential to build affective registers toward matched partners. Having control of one's emotions to avoid emotional engagement was often advised to other redditors who expressed their difficulties in finding fun on Tinder.

Interestingly, this attitudinal norm of restrictive emotionality challenges the gender script that defines women as emotional creatures. In hookup culture and cool discourse, women can perform coolness only partially, mainly regarding aesthetics but not attitudes, because the gender script induces women to be emotionally involved with hookupsto constantly question themselves about whether men's attitudes signal further development of the relationship (Barker et al., 2018; Ticknell, Chambers, Van Loon, \& Hudson, 2003). On Tinder, however, the emotional sphere is not shown, regardless of whether women actually do such emotional work. Seemingly, relatively more venues of coolness are available to women. This is strengthened by the visual presentation of coolness, which, I explain later, exacerbates criticisms of women for being superficial.

Meanwhile, the economy of visibility as Tinder's operative principle highlights the norm of cool presentation through visibilities (Duguay, 2017; Peterson, 2014a). For male users in particular, drawing women's attention by making themselves visible was frequently advised: "HIT THE FUCKING GYM . . . Care about your looks. Trim yourself. Everywhere. The beard, the chest hair, the armpits, down there" (male).

However, the highlighted emphasis on visibility as part of cool presentation on Tinder ironically engenders skepticism among users. On Tinder, where the imagination of a person is mostly organized around visual cues, the performance of coolness as an attitudinal norm featuring emotional detachment unlikely yields deep engagement with a person's psychological aspects. Heavy investments in visual presentation rather engender skepticism on Tinder because, according to the contemporary cultural doctrine of psy-discipline, the psychological attributes of the self are believed to carry the values of authenticity, truth, realness, and ontology (Illouz, 2007). Unlike the psychological self, associated with the authentic interiority, the visual presentation of coolness may not contribute to the value of authenticity, rather undermine it as the convention of visual coolness reproduces heterosexual normativity with corporeality. In turn, visually presented Tinder users with nonchalant attitudes are likely built as objects of shallowness only with visibilities lacking such psychological attributes. Based on the cynicism toward entities established with corporeal visibilities, redditors skeptically linked the visual cool presentation with nonchalance to lightness and superficiality as Tinder's overall image, far from authenticity: "Tinder is the wrong place to go if you're not good looking, because it tends to be for hookups and based more on appearance" (female).

Cynicism toward Tinder was pervasive on $/ \mathrm{r} /$ Tinder. Cassidy (2018) argues that apps like Tinder and Gaydar evoke users' dismissive attitudes toward the medium and 
make users reluctant to engage with other users because of stereotypes inherent to the imagined users (e.g., sexually promiscuous gays), what he calls "participatory reluctance." Likewise, I found redditors showed participatory reluctance toward Tinder and redefined the purpose of Tinder in their own terms:

I see Tinder as a hot or not app, not really as a dating app. I use it more to check out attractive people near me ... I think a lot of people might use it this way too. (Female)

The collectively performed participatory reluctance, interestingly, altered the functional meaning of Tinder for some users, not necessarily getting involved in interactions with other users. As Cassidy (2018) argues, widely repeated participatory reluctance among users shapes a culture of a media platform rife with cynicism and suspicion rather than remaining as an isolated personal orientation. The participatory reluctance of Tinder users seen above was frequently addressed as one aspect of Tinder culture. The repeated participatory reluctance negatively influenced the overall quality of interactions between users. Notably, it led to backlash and reversed skepticism toward those who showed participatory reluctance. Whereas Tinder itself strived toward authenticity by syncing users' Facebook or Instagram accounts (Duguay, 2017), its user behaviors strengthened the pessimism about Tinder, doubting the value of authenticity, specifically regarding women.

\section{Misogyny}

If you're using the app to see how many guys can like you in 15 minutes that you won't message back, save everyone the trouble and get the ego boost by making some twerking video on Instagram or something. (Male)

As shown above, the reversed skepticism criticized condescendence, shallowness, and superficiality as behavioral characteristics of female Tinder users. According to this perspective, underlying the superficiality of female Tinder users were acts of self-validation and ego-boosting via the app. The cynical posts about female Tinder users on /r/Tinder can be linked to Reddit being a manosphere, featuring misogyny, anti-feminism, and gender-trolling (Mantilla, 2015; Massanari, 2017; Milner, 2013). Reddit's upvote system may strengthen it, as a "tyranny of the masses," pressing down different and more gender-neutral perspectives (Milner, 2013). I further pose that hookup culture ignites such a manosphere aspect of Reddit adroitly in Tinder discourse.

Studies about hookup culture criticize the coercive gender system inherent to the culture in which both men and women are forced to perform hegemonic masculinity and passive femininity, respectively (Bogle, 2008; Freitas, 2013). As evidenced in those studies, this culture is violent for women, rife with threats of toxic masculinity like slut-shaming and rape. Noticeably, however, the system also operates in a canny way, inducing them to know their position to be desired while ignoring women's voices, instead of threatening women with toxic masculinity. This was found on $/ \mathrm{r} /$ Tinder as two types: (1) kind advice for female Tinder users to be cool and (2) peremptory judgment about female users' disinterest in hookups that is written on their bios, based on the "Tinder = hookup" reading.

In one thread asking if girls can message guys first, redditors recited the female version of coolness:

In all cases that a girl opened I went on like it is the most normal thing (come on it is), some dudes seem to get intimidated by it though. (Male)

Don't be afraid to challenge a guy about being complacent. "So do you just give good chat or do you actually get out and meet the girls on here? I've never been to some batting cages, you seem like just the guy to go to one with. Down?" A girl who wants to put her hands on a hard phallus shaped object and play with balls is subconsciously suggestive (can't be too subtle, us boys can be pretty dumb) and you're challenging him in a nonthreatening, non-bitchy way. I advise against putting such a challenge in your profile. It will lose your more prospects than it will win. (Male, my emphasis)

The accounts above restrict women's sexual agency based on the sexual double standard for women in hookup culture. Nevertheless, gendered advice in the accounts may be appreciated by women as "Tinder tips" because they are addressed for women with care. Yet they are premised upon, and reproduce, the socially desirable femininity, as in the cool girl figure, which is sexually active but tame and accommodating men's sexual desire, unlike "intimidating or threatening bitches."

Problematically, as these advices are premised upon the "Tinder = hookup" logic, female users' disinterest in hookups is adamantly dismissed as women's typical gesture to passively indicate their desire for hookups, although women unequivocally note on their bios: "not for hookups," "not DTF [down to fuck].”

I'm pretty sure a large amount of girls who put "not looking for a hookup" are NOT going to be opposed to hooking up if the chemistry is flowing after a short amount of time. I just think a lot of girls are just putting that out there because they're afraid of looking outwardly slutty and/or being judged.

Despite Tinder's reputation as a hookup app, women often avoid hookups but use the app for various reasons (Lee, 2019). Reading Tinder as a hookup app, however, dismisses the variety in reference to the conventional male rhetoric to justify rape: "women's 'no' means 'yes"” (Osman, 2003). This is dangerous not only for the continuation of the rape rhetoric but also for a chance of actual sexual harassment in reality via Tinder. Tinder then becomes a site of violent 
sexism, evidenced in many women's testimonies online (Hess \& Flores, 2018; L. Thompson, 2018).

The quoted accounts above are less aggressive, compared with sexual harassment documented in other studies (Hess \& Flores, 2018; L. Thompson, 2018). However, they revolve around the manosphere of Reddit and pornographic hookup culture. That is, they can break out as misogyny and attack women any time if fuel is given. The fuel, I contend, is women's visibility obtained from coolness.

As noted earlier, cool has been part of male territory (Pountain \& Robins, 2000). Women can perform coolness aesthetically because of women's embodied duty of aesthetic labor, but they cannot fully perform regarding attitudes because the attitudinal coolness and the resultant air of confidence conflict with the gender script that defines women as emotional creatures requiring male protection (Ticknell et al., 2003). Cool norms in the visual centered mechanism of Tinder, however, disrupt this male ownership of coolness because Tinder and its norm, cool, contradict the traditional gender script by hardly offering women a chance to show their emotionality. From there, a tension between the gender system and cool emerges and troubles those who subscribe to the gender script. I argue that the pessimism toward Tinder users who concentrate on visual presentations easily falls into the trap of this trouble and echoes in a misogynistic tone in Tinder discourse, meeting the established manosphere culture of Reddit:

Tinder is really only a successful means of meeting people for the upper echelons of aesthetically appealing people. That's just the way it is ... Most the girls on there are the narcissistic type to take a million selfies and go clubbing all the time.

Banet-Weiser (2018) argues, the "encroachment of women in a traditional male domain" is an issue that leads to male insecurity and crisis expressed in popular misogyny (p. 159). Increased visibilities of female users who invested in their self-presentation, then, are enough to intimidate men, especially those males who are not in the "upper echelons of aesthetics." For them, women who observe cool norms on Tinder (i.e., aesthetically visible and emotionally nonchalant) may appear to threaten male existence, based on the zero-sum game logic of popular misogyny (Banet-Weiser, 2018).

Heterosexuality becomes a battlefield for popular misogyny to rectify the gender balance back to the patriarchal relation (Banet-Weiser, 2018; R. O’Neill, 2015; Ringrose, Harvey, Gill, \& Livingstone, 2013). On Tinder, which mediates (hetero)sexual intimacy, popular misogyny that is widely spread around male-dominant sites like Reddit easily breaks out reacting to the biggest threat, "the upper echelons of aesthetically appealing women" who appear confident, harnessed with their visibilities, and may not need validation from relatively less-visible men. Ultimately, the superficiality of Tinder, shaped by users' participatory reluctance, serves as a good resource to feed popular misogyny. The skepticism toward the entity of corporeal visibilities legitimizes misogynist discourses:

Around where I live it's just full of vacuous twats looking for an ego boost and Instagram followers or the generic, prudish dullards who have "Live, love, laugh, travel, friends" as their "interests" and their profile is basically a photo reel of them with various drugged animals. Fuck I just want to meet someone fun and normal. Someone with actual interests. (Male)

If I see one more profile with "just a blahblahblah Tinderella suffering from a serious case of wanderlust" I'm gonna smash my phone. Just write something real; be a real person. (Male, original emphasis)

According to Illouz (2007), superficiality is an inherent irony of online dating. When information about one's psychological entity is required, as in OkCupid, people tend to apply conventions of social desirability in self-presentations by describing themselves with attributes desirable in the dating market: outgoing, funny, and positive (Illouz, 2007). In this case, one's visibility becomes the measure available to distinguish and value a person among others who present the same psychological self or who do not provide enough information. Thus, regardless of whether one's psychological self is sufficiently provided, a visual regime works powerfully in the construction of intimacy online. Ironically, whereas the visual displayed in pictures is considered the value of the self in competition with others, it is also regarded as superficial and shallow, unlike the authentic interiority of the self. Therefore, "common" profiles that read "Live, love, laugh, travel, friends" are not likely appreciated by users, but rather exacerbate criticism of female users for being "superficial and not real."

Furthermore, the gendered irony of cool norms on Tinder conceals the misogynistic tone in criticism of female Tinder users. Whereas it provokes a tension in the gender system by detaching emotionality from female users, the cool norm is still gendered by demanding aesthetic labor upon women to be heterosexually desirable. This ironically provides an excuse to reasonably criticize women who follow the old gender script and heavily invest in visualization of their bodies as being "typical" women:

Male says: Marilyn Monroe was NOT a philosopher, I don't care about your Instagram . . . only swipe right if you will at least ATTEMPT a conversation.

If the woman swiped right first, I like it if a woman could actually start a conversation and add something to the conversation. I thought that women wanted equality in this country? That means that chivalry goes out the window. (Male)

Due to the gamified design of Tinder in which fun is mainly driven from the flow of swiping, engaging with relatively old matches can be difficult or delayed for users. As 
some redditors noted, Tinder matches often elude their attention when they have already recorded many matches. Nevertheless, premised upon gender distinction and heteronormativity, the male redditors above ascribed participatory reluctance to women and legitimatized such accusations in line with a misogynistic tone. This criticism is, however, rarely noticed as misogyny, as it appears reasonable to blame women for being feminine. Thereby, women also unconsciously subscribe to the misogynistic tone inherent in the dominant way of reading Tinder as a hookup app and depoliticize prevailing violence in the discourse:

Look, Tinder is where (objectively attractive) superficial people go to find validation and/or dates from equally (objectively attractive) superficial people. If you're "rather plain" and "comically bad at taking selfies" then Tinder is simply not for you. PoF or OKC would be my suggestions for what you're looking for. If you're hellbent on using Tinder though, I'd say work on your makeup skills and practice taking pictures from better angles. (Female)

If $/ r /$ Tinder is a place where users share their individual experiences and shape imaginary collective experiences and norms of Tinder, the unnoticeably spread misogynistic tone can easily permeate in Tinder culture and affect their Tinder use. When this discourse proliferates, Tinder is only treated as a site of violence where "superficial people meet equally superficial people." Given the tone of "just for fun," users are likely to engage in problematic behaviors associated with pornographic images of hookups, especially toward women, including textual and visual harassment, regardless of however people join and use Tinder. On/r/Tinder, many redditors posted profile pictures of female users whom they encountered on Tinder without those women's consent. Both male and female redditors judged the "fuckableness" of those women and made fun of them. Some female redditors' serious criticisms toward these posts, albeit rare, were dismissed as their fault for not getting it right because, as quoted earlier, it is believed that "Tinder is a damn sex app ... This isn't 'Dating' site at all."

\section{Conclusion}

This case study on $/ \mathrm{r}$ /Tinder showed that Tinder's visual centeredness reinforces the gender system and feeds online misogyny by interacting with the existing gender script intrinsic to cool discourse and hookup culture. Projecting discourses on $/ \mathrm{r} /$ Tinder into popular misogyny yields three interrelated implications. First, as studies have criticized, cool discourse and hookup culture are not available equally to women and men (Barker et al., 2018; Ticknell et al., 2003). Rather, because of cynicism toward corporeality as opposed to an "authentic" and "true" psychological self, the image of women with confidence and freedom, armed with visibilities, is vulnerable itself, facing defamation for being obsessed with corporeal femininity and being arrogant and shallow (Gill \& Kanai, 2018). Considering the depoliticized atmosphere in the economy of visibility (Banet-Weiser, 2018; Gray, 2013), this criticism of women reinforces the gender distinction as a fait accompli, not challenging the gendered politics inherent to the economy of visibility.

Second, reading Tinder as a hookup app on $/ \mathrm{r} /$ Tinder is one example of how the online has already been intoxicated with pornographic violence innate in hookup culture, which can easily break out in a violent form anytime. The contemporary mediascape provides a canny way that the forcible gender system tames users in violent environments not necessarily exercising obvious toxic masculinity, such as sexual harassment and rape. Despite sexual aggression in hookup culture (Freitas, 2013), the prevailing toxicity hampers people from noticing violent features of the gender system but leads them to accommodate themselves in it by sharing tips to be successful in the market of intimacy.

Third, this intoxicated environment is dangerous as it can involve actual violence. Intimacy as the most private realm is, indeed, the most vulnerable to violence; media platforms for intimacy bear these problems. While this essay mainly covered heterosexuality because of Tinder's heterosexualityfocused setting (Duguay, 2017), many studies about mobile apps for intimacy have documented pervasive violence against minorities (e.g., non-White queer), which is uncritically conducted as "personal taste" (Conner, 2019; Shield, 2017). Problematically, this violence entails physical violence as intimacy does not strictly distinguish between offline and online but rather crosses the boundary.

The worrisome attention of society to Tinder or youth pairing culture, by relating them to the dating apocalypse, does not discuss the old gender system in heterosexuality in which women have long been treated as objects; but it nostalgically fantasizes the idea of romantic love. It criticizes a good chance of sexual violence upon women on Tinder, but the criticism only covers the extreme far-right violence while overlooking the violence of the gender system that has long existed prior to Tinder. Toxicity in hookup culture and Tinder is very close to our daily lives in the form of popular misogyny: kind advice for women to be a cool girl, referring to a sexual double standard for women, and ignorance of women's disinterest in hookups (Banet-Weiser, 2018). Popular misogyny's collusion with heteronormativity gradually intoxicates both men and women by taking the form of what is seen as reasonable criticism toward women. On Tinder, women are continuously compelled to be "women," and women are simultaneously chided as either superficial (when following the cool norm) or uncool (when not following this norm). Then, nothing is cool.

\section{Declaration of Conflicting Interests}

The author(s) declared no potential conflicts of interest with respect to the research, authorship, and/or publication of this article. 


\section{Funding}

The author(s) received no financial support for the research, authorship, and/or publication of this article.

\section{ORCID iD}

Jin Lee (iD https://orcid.org/0000-0002-5698-5561

\section{Note}

1. This does not mean race is insignificant in Tinder experiences. Race was often found on /r/Tinder regarding nonWhite males' difficulties in finding Tinder matches, but rare in non-White women's cases. For the study purpose that examines women's experiences, I did not include non-White males' raced Tinder experiences here. Unlike/r/Tinder, however, race was frequently mentioned by non-White women in in-depth interviews, not as a barrier to matches but as a facilitator and framework to lead their experiences in particular ways (Lee, 2019).

\section{References}

/r/Tinder. (2019). /r/Tinder wiki: History. Retrieved from https:// www.reddit.com/r/Tinder/wiki/history

Abidin, C. (2014). \#In\$tagLam: Instagram as a repository of taste, a burgeoning marketplace, a war of eyeballs. In M. Berry \& M. Schleser (Eds.), Mobile media making in an age of smartphones (pp. 119-128). New York, NY: Palgrave.

Adkins, L., \& Lury, C. (2011). Introduction: Special measures. The Sociological Review, 59(2, Suppl.), 5-23.

Atkinson, P. (2014). The ethnographic imagination: Textual constructions of reality. London, England: Routledge. (Original work published 1970)

Bailey, B. L. (1989). From front porch to back seat: Courtship in twentieth-century America. Baltimore, MD: Johns Hopkins University Press.

Banet-Weiser, S. (2012). Authentic TM: The politics and ambivalence in a brand culture. New York: New York University Press.

Banet-Weiser, S. (2018). Empowered: Popular feminism and popular misogyny. Durham, NC: Duke University Press.

Barker, M.-J., Gill, R., \& Harvey, L. (2018). Mediated intimacy: Sex advice in media culture. Cambridge, UK: Polity Press.

Bogle, K. A. (2008). Hooking up: Sex, dating, and relationships on campus. New York: New York University Press.

Cassidy, E. (2018). Gay men, identity and social media: A culture of participatory reluctance. London, England: Routledge.

Conner, C. T. (2019). The gay gayze: Expressions of inequality on Grindr. The Sociological Quarterly, 60, 397-419.

Couldry, N. (2010). Why voice matters: Culture and politics after neoliberalism. London, England: SAGE.

Currier, D. M. (2013). Strategic ambiguity: Protecting emphasized femininity and hegemonic masculinity in the hookup culture. Gender \& Society, 27, 704-727.

De Choudhury, M., \& De, S. (2014, June 1-4). Mental health discourse on reddit: Self-disclosure, social support, and anonymity. Paper presented at the Eighth International AAAI Conference on Weblogs and Social Media, Ann Arbor, MI.

D'Emilio, J., \& Freedman, E. B. (1989). Intimate matters: A history of sexuality in America. Chicago, IL: University of Chicago Press.
Deterding, S., Dixon, D., Khaled, R., \& Nacke, L. (2011, September 28-30). From game design elements to gamefulness: defining gamification. Paper presented at the Proceedings of the 15th International Academic MindTrek Conference: Envisioning Future Media Environments, Tampere, Finland.

Duguay, S. (2017). Dressing up Tinderella: Interrogating authenticity claims on the mobile dating app Tinder. Information, Communication \& Society, 20, 351-367.

Fincham, B. (2016). The sociology of fun. London, England: Palgrave.

Frank, T. (1998). The conquest of cool: Business culture, counterculture, and the rise of hip consumerism. Chicago, IL: University of Chicago Press.

Freitas, D. (2013). The end of sex: How hookup culture is leaving a generation unhappy, sexually unfulfilled, and confused about intimacy. New York, NY: Basic Books.

Gill, R., \& Kanai, A. (2018). Mediating neoliberal capitalism: Affect, subjectivity and inequality. Journal of Communication, $68,318-326$.

Gray, H. (2013). Subject(ed) to recognition. American Quarterly, $65,771-798$.

Hartmann, H. I. (1981). The family as the locus of gender, class, and political struggle: The example of housework. Signs, 6, 366-394.

Hess, A., \& Flores, C. (2018). Simply more than swiping left: A critical analysis of toxic masculine performances on Tinder Nightmares. New Media \& Society, 20, 1085-1102.

Hine, C. (2000). Virtual ethnography. London, England: SAGE.

Illouz, E. (1997). Consuming the romantic utopia: Love and the cultural contradictions of capitalism. Berkeley: University of California Press.

Illouz, E. (2007). Cold intimacies: The making of emotional capitalism. Cambridge, UK: Polity Press.

Iqbal, M. (2019). Tinder revenue and usage statistics (2018). Retrieved from http://www.businessofapps.com/data/tinder-statistics/

Jenkins, R. (2007). Pierre Bourdieu. London, England: Routledge. (Original work published 1992)

Kupers, T. A. (2005). Toxic masculinity as a barrier to mental health treatment in prison. Journal of Clinical Psychology, 61, 713-724.

Lee, J. (2019). Talking about race and gender with Tinder: Raced and gendered visibility of non-white women (Doctoral dissertation). Southern Illinois University Carbondale. Retrieved from https://opensiuc.lib.siu.edu/etd/

Levy, A. (2010). Female chauvinist pigs: Women and the rise of raunch culture. New York, NY: Free Press.

Mantilla, K. (2015). Gendertrolling: How misogyny went viral. Denver, CO: ABC-CLIO.

Massanari, A. (2017). \#Gamergate and the fappening: How Reddit's algorithm, governance, and culture support toxic technocultures. New Media \& Society, 19, 329-346.

Milner, R. M. (2013). FCJ-156 Hacking the social: Internet memes, identity antagonism, and the logic of Lulz. The Fibreculture Journal, 22(Trolls and The Negative Space of the Internet). Retrieved from http://twentytwo.fibreculturejournal.org/fcj156-hacking-the-social-internet-memes-identity-antagonismand-the-logic-of-lulz/

O’Neill, R. (2015). The work of seduction: Intimacy and subjectivity in the London "seduction community." Sociological Research Online, 20(4), 1-14. 
O’Neill, T. (2018). “Today I speak": Exploring how victim-survivors use Reddit. International Journal for Crime, Justice and Social Democracy, 7, 44-59.

Osman, S. L. (2003). Predicting men's rape perceptions based on the belief that "no" really means "yes." Journal of Applied Social Psychology, 33, 683-692.

Peterson, A. H. (2014a, September 11). How I rebuilt Tinder and discovered the shameful secret of attraction. Buzzfeed News. Retrieved from https://www.buzzfeednews.com/article/annehelenpetersen/we-are-all-classists

Peterson, A. H. (2014b, February 28). Jennifer Lawrence and the history of cool girls. Buzzfeed News. Retrieved from https:// www.buzzfeed.com/annehelenpetersen/jennifer-lawrenceand-the-history-of-cool-girls?utm_term=.siK884Aed\#. iaqqqy01X

Pountain, D., \& Robins, D. (2000). Cool rules: Anatomy of an attitude. London, England: Reaktion Books.

Ringrose, J., Harvey, L., Gill, R., \& Livingstone, S. (2013). Teen girls, sexual double standards and "sexting": Gendered value in digital image exchange. Feminist Theory, 14, 305-323.

Sales, N. J. (2015, August 6). Tinder and the dawn of the "dating apocalypse." Vanity Fair. Retrieved from www .vanityfair.com/culture/2015/08/tinder-hook-up-culture-end -of-dating

Shield, A. (2017). "Looking for north Europeans only": Identifying five racist patterns in an online subculture. Kult-Postkolonial Temaserie, 15, 87-106.
Stearns, P. N. (1994). American cool: Constructing a twentieth-century emotional style. New York: New York University Press.

Thompson, L. (2018). "I can be your Tinder nightmare": Harassment and misogyny in the online sexual marketplace. Feminism \& Psychology, 28, 69-89.

Thompson, R. (2019, June 7). In the dating game, women are pressured to play the part of a stereotypical "cool girl." Mashable. Retrieved from https://mashable.com/article/cool-girl-stereotype-dating-culture/?europe=true

Ticknell, E., Chambers, D., Van Loon, J., \& Hudson, N. (2003). Begging for it: "New femininities," social agency, and moral discourse in contemporary teenage and men's magazines. Feminist Media Studies, 3(1), 47-63.

Van der Nagel, E. (2013). Faceless bodies: Negotiating technological and cultural codes on Reddit Gonewild. Scan: Journal of Media Arts Culture, 10(2), 1-10.

Wiegman, R. (1995). American anatomies: Theorizing race and gender. Durham, NC: Duke University Press.

\section{Author Biography}

Jin Lee is a PhD candidate in the College of Mass Communication and Media Arts at Southern Illinois University Carbondale. Her research interests include digital culture, feminism, and online intimacy. Her work appears in the Journal of Critical Studies in Media Communication, Broadcasting \& Communication (Korean Journal), Media, Gender, and Culture (Korean journal). 